\title{
Green technologies in sustainable urban planning
}

\author{
Suaad Laffta ${ }^{1}, *$ and Areaj Al-rawi ${ }^{1}$ \\ ${ }^{1}$ Center of urban and regional planning for post graduate studies, Baghdad University, Baghdad, Iraq
}

\begin{abstract}
The world is facing many environmental and economic problems resulting from rapid urbanization and over-exploitation of available resources as well as due to the dramatic increase of the population and corresponding increases in the number of cities. Technological and industrial development plays a big role in these problems. As a result, the term green technology became as a tool to solve these problems with an orientation towards sustainable development at all levels. , It seems to be very effective tool in modern urban planning which incorporates of all aspects of planning such as infrastructure and industry, energy, telecommunications, transportation and other vital areas in cities. These technologies are environment friendly inventions that often involve - energy efficiency, recycling, safety and health concerns, renewable resources, and more. Green technologies include several forms of technology that help to minimize negative effects on the environment and create new ways to achieve sustainable development. This paper is about green technology and its role in sustainable urban planning, it aims to clarify the most important areas for the application of this technology and the benefits provided by these technologies in improving the lives of the population in cities and a development orientation towards sustainability.
\end{abstract}

\section{Technologies applied to urban sustainable development}

Cities face a lot of problems and challenges resulting from the significant expansion due to population growth, which increases pressure on the infrastructure and results in depletion of natural resources, as a result, the concept of sustainability came up to address these challenges and guide urban development, to ensure the sustainability of resources and reduce environmental problems. Using modern technology can overcome a lot of problems in cities and guide the planning of these cities towards sustainability. These techniques help cities to achieve an appropriate standard of living and at the same time maintain natural ecosystems and resources. Technology used to make production processes more efficient, finding solutions to various "threats" that may affect the ability of cities to compete, such as the use of soil and urban transport, waste management in the city, quality of air, cultural heritage of cities, urban information systems, sustainable energy, agriculture, and new building materials applied to urban development and sustainable water management, [1].

These techniques are known as green technologies which are just tools to helpe make cities sustainable and provide inhabitants with a good quality of life. For example in large and important cities, the integration of technologies into urban planning policies has improved many of the major problems, [2]. In the past, the technological factor has not been as important as it is now to achieve sustainability through urban planning. Currently, the challenges are more difficult, and technology is needed not only to solve technical issues related to energy, water, materials and construction, but also to develop important sectors of the city such as transportation, infrastructure, communications and housing, to make these sectors sustainable through the application of green technology, [3] .

Green technologies are environment friendly inventions that often involve - energy efficiency, recycling, safety and health concerns, renewable resources, and more, [4].

Green technologies reduce waste and contaminants, resource consumption and increase the efficiency of services in the city. The various aspects of green technology that can be incorporated into the spatial planning process help find new ways to achieve sustainable development by reducing the negative impacts of various economic and human activities on the environment and ecosystems and guiding development towards adoption of green and eco-friendly ways of life in cities and urban areas. For example, promoting green transport can enhance access to services and help reduce pollution levels and health inequities of the city's population; the use of treated wastewater in public water and green gardens help to reduce overall water consumption. Cities should look at circular development models that recycle water and waste and produce energy in them, so that sewage can be used, for example, to grow fish, plants or recycled solid waste to create methane. These initiatives help to reduce harmful

\footnotetext{
*Corresponding author: $\underline{\text { dr.suaad.j@,iurp.uobaghdad,edu.iq }}$
} 
environmental impacts improve the city's landscape and improve quality of life, [5].

"The greening of cities will require some, or preferably all, of the following, [6]:

- $\quad$ "Reduction of chemical and physical hazards".

- $\quad$ "Control over environmental impacts on health".

- "Creation of quality environments for all"

- $\quad$ Minimized ecological footprints outside the urban area".

- $\quad$ "Ensured sustainable consumption".

- $\quad$ "Adaptation to climate change impacts".

Buildings, energy, and transport are the largest sources of $\mathrm{CO} 2$ emission and through design strategies and technologies to improve building construction, urban transport efficiency, and technology to generate energy, water management and waste management, the amount of emissions can be reduced. Depending on the green technologies, all this will reduce the rate of energy and natural resources consumption.

"There are four eco-technologies that may be utilized by city planners and other professions the urban planning and design: "Environmental Technologies (ET)" encompass a broad range of technologies related to energy, water, and waste, while "Information Technologies (IT)" include a broad range of computerbased hardware and software and environmental sensing technologies for gathering of environmental data. "Geographic Information systems (GIS)" provide for the storage, transformation, manipulation, management, visualization, updating, querying, and reporting in related databases of geo-referenced data in a tabular format, and incorporates an Urban Information System that facilitates land use analyses, the preparation of development and environmental plans, etc. Finally, "Communication Technologies (CT)" are used for the transfer of environmental data, information, knowledge, and decisions in wired or wireless environments", [7] .

These green technologies are one of the most important and effective tools for achieving sustainable development in cities by contributing to the greening of economic, service and urban sectors and preserving natural resources because they enable planners to choose the best pathways to minimize the negative effects of development and maximize the benefits.

\section{Green technology and efficiency of energy}

Energy is one of the most important elements upon which life depends in modern cities, and is the main engine for all core activities in these cities. It also represents one of the main causes of environmental problems in cities because it is produced from nonsustainable sources, therefore, the production of energy in cities by using green technology is very important in order to achieve sustainability of these cities. Investments in renewable energy today are likely to gain benefits in the coming years. Renewable technologies are usually more labour-intensive than fuel-based power generation projects, they have positive effects of being clean and non-polluting energy and rely on nonexhaustive sources, [8].

Unplanned urban expansion increases energy demand and carbon emissions, thereby distorting the ecosystems and making cities socially divisive places to live. This process is called the "negative ecological footprint". The key to meeting growing future energy demand is obtaining energy from clean, non-traditional sources. Diversification of renewable energy supply must extend into solar, wind, geothermal, ocean wave, and tidal energy sources, [9].

The investment in low-carbon technology is expected to extends significantly in the future, more than 460 billion $\$$ will be invested in renewable energy projects globally by 2030, [10]. Achieving benefits from using clean energy sources without losing social and economic benefits of urban areas is the key goal for the future, [11].

In several urban cities, the traditional grid model of electricity generation is being re-examined. The smart grid, which changes the urban energy landscape, is being used. These intelligent networks operate efficiently in cities and will play an important role in changing the way power is generated and distributed in the future, [8].

\section{Sustainable and green infrastructures.}

Infrastructure is the basis on which modern cities, activities and population depend, It represents the basic structure of these cities which urban growth and economic development and the life quality of its population depend.

Due to global climate change, which leads to increased frequency of storm, rising temperatures and rising sea levels, some countries have resorted to green infrastructure as a hedge against the risks of climate change, [12].

Recently green infrastructure and technologies have been identified as 'best practices' at the local level when combined with traditional grey and it focuses on prevention of unnecessary consumption of natural resources (especially non-renewable ones) and mitigation of harmful emissions, [13].

The US Environmental Protection Agency (EPA) defines sustainable infrastructure as a range of practices that "encourage utilities and their customers to address existing needs so that future generations will not be left to address the approaching wave of infrastructure needs that will result from aging infrastructure", [14].

The term green infrastructure is a new term, but it is not a new idea that began a hundred and fifty years ago through planning and preservation efforts through two concepts:

- Link parks and open areas.

Conservation and linkage of natural areas to biodiversity, [15]

The importance of green infrastructure can be summarized, [16]

- Sustainable management of land and water resources, including production (eg energy and food crops), 
pollution control, climate improvement, increased land cover porosity,

-Biodiversity.

- Recreation - through the corridors or green roads and the use of methods to contribute to improving the quality of life and public health.

- Aesthetic - because of the green spaces and corridors of beautiful landscapes.

The sustainability of human habitats is directly related to the sustainability of natural habitats, so when planning sustainable infrastructure to balance them, it is essential to adopt green infrastructure, [17].

Green infrastructure approaches help adapt to climate change. Their ability to mitigate the effects of heavy precipitation and temperature reduction, better management of storm water runoff, and water retention and conservation, [12].

The use of these approaches in the planning process for sustainable cities will support the resilience of cities to the effects of climate change and adaptation to climate change and help reducing the impact of climate change on people's lives and natural resources.

Green infrastructure helps to preserve arable land and reduce the consumption of this valuable resource, in addition to conserving natural green areas. These green structures also help reduce hazardous waste and thus improve the quality of life and public health.

\section{Sustainable planning of housing}

Due to population growth, urbanization, poverty, inequality, pollution and overcrowding, which necessitated UN-Habitat to develop new approaches and standards and urban planning systems to address them. To achieve these goals they put five principles, [18 ]:

- The allocation of sufficient and efficient space for the street network, and $30 \%$ of the master plan, and not less than $18 \mathrm{~km}$ per $\mathrm{km} 2$.

- Achieve a high population density of 15,000 people / $\mathrm{km} 2$, ie 150 people / ha.

- Adopt the principle of mixed use of $40 \%$ of the land area and be allocated for commercial use.

-Social integration, through the provision of housing with different holdings of private ownership, rent, 50\% each, and provide (20-50) \% of low-income.

\section{Green technology for water treatment}

Water is one of the most valuable resources, and it must be free of pollutants to avoid risks to humans and our environment, Water treatment methods exist in traditional ways but are not sufficient to eliminate the pollutants completely which requires the development of alternatives to water purification, solar energy, which is a green technologies to get rid of water pollution.

There are four methods for solar powered water purification, [19,20]:

-Solar water treatment systems:-The water purification system is based on the use of battery operated on solar energy, and the battery can work for three days even without sunlight.

-Solar water disinfection: Water is sterilized with plastic bottles and exposed to sunlight for six hours

-Solar water pasteurization: Bacteria are killed in solarheated stoves.

- Solar distillation: It is used to desalinate sea water and make it drinkable.

\section{The information technology as a tool for sustainable urban planning}

"Geographic Information Systems (GIS) are systems of spatial location making use of geographic and statistical databases, where the characteristics and trends of a model of geographic development can be visualized", [21].

GIS is used to apply geo-knowledge to solve problems. In the case of green government decisions, geographic information systems are essential in identifying land uses and zoning.

For decades, urban and regional planners have used GIS to plan better communities, developing smart growth of cities and controlling urbanization.

Using GIS on the Internet, we can publish maps and help citizens understand the proposed plans, public awareness of plans and discussions is essential for development initiatives and for improving the ability of planners to serve the community.

The success of planners in combating chronic urban problems is largely determined by their ability to utilize effective tools and planning support systems.

The planners use GIs as a tools to achieve their goals of creating viable communities in a pollution-free environment and achieving economic development, as well as its use for analysis and modeling, [23].

There are four steps of GIs system, [23]: -Firstly: Data collection, input and correction. -Secondly: Data storage and retrieval.

-Third: Data Manipulation and Analysis Phase. -Fourth: Data Display and Reporting Phase.

\section{Green roads}

Road network design has traditionally been concerned with vehicle traffic and road safety. Now, road network design is concerned with many things such as aesthetics, environment and community interests. The landscaping of roads and green spaces gives advantages to transport corridors, [24].

\subsection{Principles of green roads concept}

The green road concept is an approach that refers to a sound and appropriate methodology either cost (low cost), environmental, technical, work-based or roadbased. 
The Green Road Concept focuses on conserving the delicate mountain ecology, in particular the protection of vegetation cover as means of soil conservation. Actually, Green Road is a low-cost, low-volume, fairweather earthen road. They are usually village roads or district roads under the rural road network and not a new class of roads in itself.

Greater emphasis is given to the selection of a smooth longitudinal alignment that allows for progressive upgrading as traffic increases. This approach is most appropriate for rural hill road construction having low traffic volume. But some aspect of Green Roads could be used in Feeder and Roads and Highways too, $[24,25]$.

\section{Countries that have the greatest potential to produce and commercialize green technology}

\subsection{Ireland}

Ireland is a strong competitor in clean technology, focusing on wind and tidal energy. There is considerable innovation progress, supported by prominent science and engineering institutions.

Clean jobs in 2020 are expected to reach 80,000, and wind farm projects for power generation of 138 megawatts, and these figures are likely to be incremental ,[26].

\subsection{Germany}

Germany continues to be a leader in the renewable energy market and occupies one-third of the world's installed solar energy, despite its often cloudy climate, and has also put plans to reduce carbon emissions by 80 $95 \%,[26]$.

\subsection{Switzerland}

Switzerland has high innovative inputs, supportive government policies, and medium-sized energy and transport infrastructure, all of which support the clean technology industry, [26].

\subsection{Canada}

The clean technology industry in Canada is still average today, although many innovative factors are in their early stages, which means that the country can make huge profits in several years, [26].

\subsection{UK}

The UK is a strong competitor in green technology innovation, currently outperforming the wind sector, and has the world's largest wind market.
And that there is a new innovator Cyber Hawk in the wind sector acts as an observer of the air infrastructure, [26].

\subsection{Denmark}

Denmark ranks first in the wind energy investment list and one of the two highest clean technology budgets with the other country Finland.

And looking for partnerships to invest in places like China and this attracts investors both domestically and abroad, [26].

\subsection{Sweden}

Sweden leads the list of clean technology innovation programs and has a number of clean technology companies as well as a major consumer of renewable energy, [26].

\subsection{USA}

There are some green initiatives, such as a $30 \%$ reduction in carbon emissions by 2030, and an increase of $30 \%$ in the fiscal year 2014 for development research and clean energy to $\$ 7.9$ billion, [26].

\subsection{Finland}

There are several factors that encourage clean technology in Finland, such as the lack of fossil fuels, severe climate and the possibility of innovation. So it operates the second largest clean technology industry, and the industry provides jobs for up to 50,000 people. This figure will double by 2020, [26].

\section{The Eco-town concept}

Eco-Town is a town where most of its activities depend on green technologies It is based on several concepts. which include the 3R (Reduce, Reuse and Recycling) concepts as well as building an economy based on the life-cycle approach and accumulation of recycling facilities. Eco-Town concepts also include extended producer responsibility, socially responsible investment, green procurement, green consumerism, industrial ecology, and integrated waste management, global reporting initiative, corporate social responsibility, green labelling, EMS and ISO 14001, [27,p1-2],see Fig.1 below. 


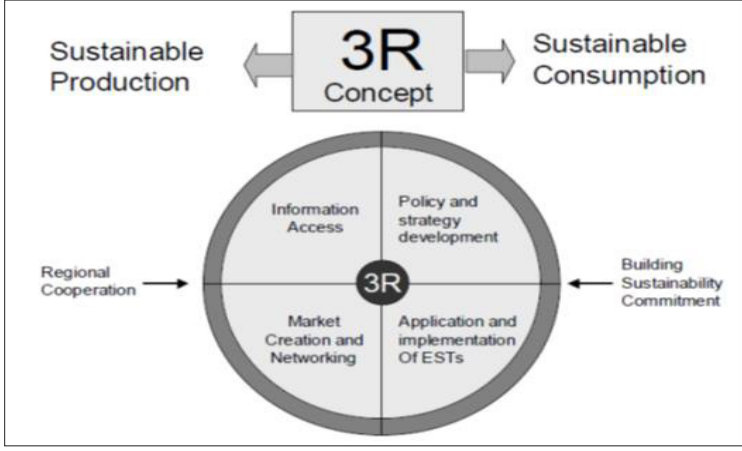

Fig. 1. Eco-town concept.

The concept of Eco-Town has been expanded, from focuses mainly on individual systems related to $3 \mathrm{R}$ to becoming part of the eco-city concept and to include industrial environmental parks, industrial solidarity and concentration on collective areas, focus generally on urban planning, urban ecosystems and other spatial planning branches. See fig. 2

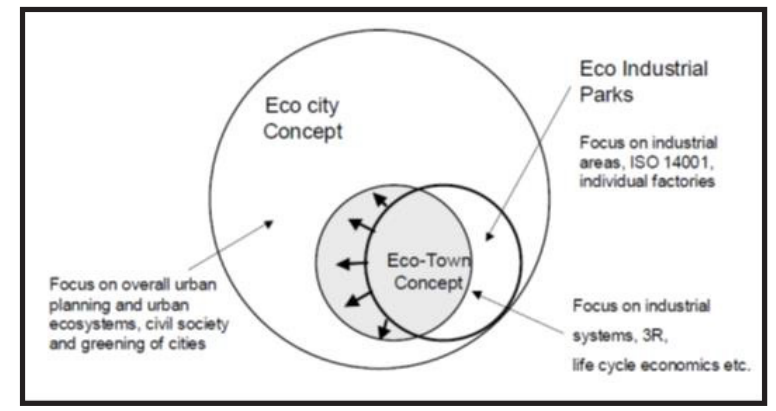

Fig. 2 Relation between Eco-City concept \& Eco-Town concept

\subsection{Kawasaki Eco-town in Japan.}

Kawasaki is the first environmental city in Japan. It is located in the coastal area of Kawasaki. It was founded in 1997 and includes several economic activities based on green technologies including plastic waste recycling system for use as blast furnace raw materials, paper recycling facility, waste recycling, Ammonia recycling system [27,p14].

The Kawasaki Eko-Toon plan aims to define a wide area to extend the entire coast of Kawasaki, Aspiring to make the community rely on recycling resources, and seek to develop the coastal zone, and to achieve these goals it plans to develop zero-emission industrial zone. Individual companies in the industrial zone will not only reduce their emissions but also effectively use or recycle emissions from other facilities there to new resources that could be used as raw materials for industry. Other recycling facilities around the industrial zone will be built To promote cooperation, where resources are recycled with existing companies and thus the production process will be circular with zero waste, [27].

\section{The Indian experience in green technology}

The emphasis will be on wind power and the road network as a green technique.

\subsection{Wind energy.}

Wind energy plays a prominent role as renewable energy in India and supports a number of means and legislation in the development of wind energy technology, Because of this support, India ranks fifth in the wind energy sectors after China, the United States, Germany and Spain. Four phases were proposed during the period (1981-2020) and the energy started from (2.2MW) during the first phase to $(23444 \mathrm{Mw})$ in 2020 . Wind energy ( $70 \%$ of the rest of the sources), as shown in the Figure, F. 3 below.

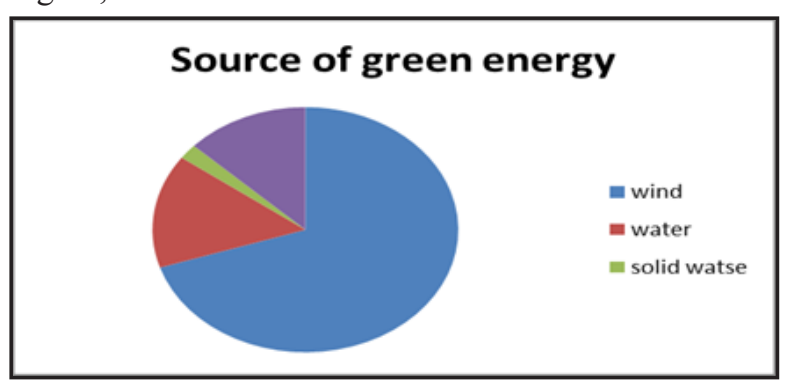

Fig.3 Green energy sources in India.

India has the world's second largest road network, the fourth rail network and the ninth civil aviation. The transport sector is expected to grow more than any other sector over the next 30 years,[28]. So a plan has been developed for the transition to green technology agencies:

\subsection{UK electric smart vehicles.}

Due to the increase in population growth and increased demand for energy, leading to increased demand for energy, and to reduce dependence on conventional fuels, emission limits and Standards have been proposed to compare with European standards by a plan of 5-10 years depending on the quality of the vehicle.

There are three companies in the Indian market:

-Riva Electric Vehicle Company

-TATA Motors.

-Bharat Heavy Electric Company.

"A plan has been put in place to produce 600,000 electric vehicles by 2020 and (40 -50 million) twowheeled vehicles and bicycles".

\section{Suggestions and recommendations for application of green technologies in Iraq}


The research will attempt to present some suggestions and recommendations for application of green technologies in Iraq through the use of these techniques in sustainable spatial planning to achieve sustainable development.

Sustainable Green Technology is one of the most important tools for sustainability in spatial planning. We will review here the most important areas in which green technology can be used to achieve sustainability in Iraqi cities:

-Energy Sector: This sector is an important sector for the lives of the population in Iraqi cities, as well as its essential role in the economic and service sector. The production of electricity in Iraq depends on the thermal stations based on oil and gas as fuel, Iraq has good sources of alternative and clean energy that can be used to generate electricity and thus eliminate environmental problems associated with the use of fossil fuels for power generation.

-Transport Sector: It is important to apply green technology in the field of transport to minimize the possible negative impacts of this sector on the environment and to achieve sustainable development. These technologies are applied through the use of mass transport based on electric trains and transport modes using electric power

-Green infrastructure: The adoption of green infrastructure in the planning of cities in Iraq is very important to address the environmental problems resulting from climate change and the acceleration of desertification of agricultural land and the high temperatures in these cities.

-Housing sector: The use of green building techniques and green architecture in the housing sector will greatly help achieve the sustainability of the housing sector in Iraq by reducing the consumption of natural resources such as land, in addition to water and energy consumption.

-Agriculture is one of the main economic activities in Iraq. The use of green technologies in agricultural sector is a necessary step to activate this sector and to overcome the problems that result from using unsustainable methods in agriculture.

- Industrial sector : industrial sector in Iraq suffers from stumbling as a result of circumstances experienced by Iraq in recent years in addition to the old methods used in the industrial sector, so the adoption of green and sustainable technologies in this sector are essential to develop this sector, and to reduce environmental, social and health problems resulting from this sector.

\section{References}

1. S. Moreno, Curent technologies appli to urban sustinable development, Faculty of Architecture and Design, Autonomous University of the State of Mexico Cerro de Coatepec s/no., Ciudad Universitaria,C.P.50100 Toluca, Estado de México, México
2. X. Chen, Urban planning management system in Los Angeles: an overview, Theoretical and Empirical Researches in Urban Management Journal, 2, (2009), pp. 50-63.

3. Commissie Lange Termijn Milieu-Beleid [CLTM]. (1990). Het Milieu denkbeelden voor, 21 ste eeuw, Kerkebosch, Zeist.

4. GH. Soni, Advanteges of green technology, Social Issues and Environmental Problems, Vol.3 (Iss.9:SE): Sep, (2015).

5. Investing in sustainable Cities, Challenges and Opportunities, International Development Finance Club Special Interest Group on Sustainable Urban Development, October (2014).

6. D. Satterthwaite, Sustainable citie s or cities that contribute to sustainable development? Urban Studies, 34 (10), (1997), 1667-1691.

7. O. Ercoskun, Green and ecological technologies for urban planning: creating smart cities, (2012)

8. .S. Hammer, Cities and green growth: A conceptual framework, OECD Regional Development Working Papers(2011), OECD Publishing. http://dx.doi.org/10.1787/5kg0tflmzx34-en

9. Rees, W. Revisiting Carrying Capacity, AreaBased Indicators of Sustainability. Population and Environment. (3), ( 1996).

10. Bloomberg New Energy Finance (BNEF). , Global renewable energy market outlook, Executive Summary. BNEF, http://bnef.com/ free publications / white-papers/ (accessed 5 April 2012).

11. UNEP, Decoupling natural resource use and environmental impacts from economic growth, Paris,(2011).

12. J. Foster, A. Lowe, S. Winkelman, , The value of green infrastructure for urban climate adaptation, The Center for Clean Air Policy February (2011).

13. R. Howes, H. Robinson, Infrastructure for the built environment-global procurement strategies; Elsevier: Oxford, UK,( 2005).

14. US Environnemental Protection Agency, Sustainable infrastructure for water and wastewater, http://www.epa.gov/waterinfrastructure. Accessed: March 12, (2009).

15. A. Mark, T. Edward, Green infrastructure: smart conservation for the 21st century, The Conservation Fund, S P R A W L W A T C H C L E A R I N G H O U S E M N O G R A P H S E R I ES.

16. R. Davies, MacFarlan, C. McGloin,More, Green infrastructuer planning guide https://www.researchgate.net/profile/Maggie_R 
oe/publication/265012095 GREEN INFRAST RUCTURE_PLANNING_GUIDE_Authors/lin ks/54f087a70cf24eb87940c8c1.pdf.

17. Planning Infrastructure to Sustain America, Next generation concepts to guide the community, design and infrastructure professions, ), p.10, (2010).

18. unhabitat for better planning future, $A$ new strategy of sustainable neighborhood planning: Five Principles.

19. P. Kalt, C. Birzer, H. Evans, A. Liew, M. Padovan, and Michael Watchman, A Solar Disinfection Water Treatment system for remote communities, The School of Mechanical Engineering, The University of Adelaide, Adelaide, 5005, Australia.

20. Dip, L. Bauer, Solar-driven water treatmentexperiences in India, Project Engineer, Solar Spring, Intersolar Europe, (2004).

21. C. Tomlin, Geographic information systems and cartographic modeling, Prentice Hall, N J,USA. (1990).

22. ESRI, GIS for Green Government Providing Sustainable Solutions.

23. ESRI, GIS for Urban and Regional Planning, January,(2011).

24. Harmonizing rural road development with mountain environment, Green roads in nepal harmonizing rural road development with mountain environment, Green Roads in Nepal Hare Ram Shrestha Director, SIDeF, Nepal Vice-President, SCAEF Nepal,( 5/30/2009).

25. Green roads: Building environmentally friendly, low maintenance rural roads through local participation Frances Klatzel GTZ Food for Work, Nepal 2000 FfW@gtz.org.np.

26. http://www.energydigital.com/top10/3708/Top10-Countries-with-Cleantech-Innovators

27. Global Environment Centre Foundation, EcoTowns in Japan -Implications and Lessons for Developing Countries and Cities, June(2005). 